\title{
Interrelation Between Livelihood Assets and Poverty in Rural Vietnam
}

\author{
TRÀ̀N TIẾN KHAI \\ Doctor of Philosophy, University of Economics HCMC \\ Email: trankhai565@yahoo.com
}

\begin{abstract}
Multi-dimensional poverty approach is currently employed in research worldwide instead of the conventional monetary-based poverty one. The Sustainable Livelihoods Approach is closely related to multi-dimensional poverty concept in terms of using a complex set of socioeconomic indicators to reflect the accessibility to five livelihood assets of household or individual, that is, the human, social, natural, physical and financial assets. This study aims at exploring interrelations between monetary poverty and other socioeconomic characteristics of rural households in Vietnam relying on livelihood approach and searching relevant socioeconomic indicators for multidimensional poverty measurement. Various multivariate analysis methods as Principal Component Analysis, Multiple Correspondence Analysis and Cluster Analysis are applied. Data of 6,837 rural households extracted from VHLSS 2008 dataset are used in this study. The results confirm that multi-dimensional poverty of rural household is explained by at least ten dimensions representative of four livelihood assets. Several continuous and categorical variables are extracted as relevant indicators for multidimensional poverty measurement. Household classification by multi-dimensional poverty is likely more statistically efficient when homogeneity with group is improved in comparison to basing on expenditure per capita.
\end{abstract}

Keywords: multi-dimensional poverty, livelihood assets, Principal Component Analysis, Multiple Correspondence Analysis, Cluster Analysis 


\section{INTRODUCTION}

Identification of poverty's nature and the way to measure poverty are concerns of development economics at the world scale because of their complexity. Appropriate poverty identification and measure will lead to better awareness of the poverty and more efficient responses by governments in poverty alleviation. The most typical point of view considers an individual or household poor if his standard living is below a threshold living standard set by a society at a point of time. Because income or consumption is the base for measurement, the poverty is seen as a monetary term. This approach can lead to two typical poverty classifications namely absolute and relative poverty.

Back to the broader concept poverty can be explained in multi-dimensional indicators (Anand \& Sen, 1977). Poverty is measured not only by income or expenditures, but also by ability to achieve food, shelter, education, health and other social living standards, and even non-physical indicators. In other words, poverty reflects the deprivation of different socioeconomic welfare which can be representing by a set of indicators. The aggregation of these indicators reflects quality of human life. There must be interrelations among indicators of multi-dimensional poverty, not simple causal relation. At present, multi-dimensional poverty measures are mostly applied by international agencies. The most popular applied indexes are Human Poverty Index (HPI) developed by Anand and Sen (1997), Human Development Index (HDI) used by the United Nations, and the Multi-dimensional Poverty Index (MPI) built by Oxford University and UNDP basing on methodology developed by Alkire and Foster (2007).

In Vietnam most studies of poverty have used uni-dimensional approach so far. Nevertheless, in recent years, several poverty studies have started applying multidimensional approach (Hà Nội People's Committee, HCMC People's Committee \& UNDP, 2010; GSO, 2010; UNDP, 2011). In these studies multi-dimensional poverty is presented as an aggregation of the separate socioeconomic aspects. However, relations among these socioeconomic indicators including monetary income and expenditures are not yet deeply clarified. In other words, the selection of dimensions and indicators of each dimension are not clearly explained.

If appropriate dimensions and indicators are selected, multi-dimensional poverty measure will be more precise. This study therefore aims at finding interrelations 
between monetary poverty and other socioeconomic characteristics of households relying on livelihood approach from which multi-dimensional poverty can be deeper understood. From these relations, appropriate socioeconomic indicators for multidimensional poverty can hopefully be found for further poverty measurement. The overall objective of the study is to explore and evaluate poverty in its multidimensional nature, in particular the interrelations among main socioeconomic aspects. The application of livelihood assets in linking with multi-dimensional poverty concept is the core of this study.

Specific objectives of the study are: (1) to find appropriate indicators representative of poverty in economic, social and cultural aspects; (2) to understand the interrelations among the multi-dimensional indicators; (3) to know how household poverty can be classified by application of an aggregated multi-dimensional indicator; and (4) exploring differences in classifications by monetary poverty and multi-dimensional poverty.

\section{THEORETICAL BASIS, ANALYSIS FRAMEWORK AND METHODOLOGY}

\section{a. Measuring Poverty:}

Normally, poverty assessment is realized by using dataset collected at national scale through a living standards measurement survey. Household composition, consumption patterns including food and non-food, assets including housing, landholding and other durables, income and employment in agriculture, non-agriculture and wage and selfemployment, socio-demographic variables including education, health, migration, fertility, and anthropometric information are important information collected. Poverty measure can be done based on these collected information, but subject to conceptual approaches.

In Vietnam, the monetary approach is often applied by GSO when conducting the Vietnam Household Living Standards Survey (VHLSS) and by Ministry of Labor Invalids and Social Affairs (MOLISA). MOLISA usually applied absolute poverty based on per capita income poverty line. The income poverty lines were separately set for rural and urban regions for different periods as 2001-2005 and 2006-2010 [1] then afterwards. Meanwhile GSO often applied both absolute and relative monetary poverty and measured poverty by both per capita household expenditures and income. In the most recent report [2], GSO (2010) used per capita income quintiles to classify 
households by poverty, a relative poverty method. World Bank (2003) also indicated that poverty measure methods that have been applied in Vietnam can be classified in six categories: (1) household expenditures; (2) poverty mapping; (3) income-based; (4) local classification; (5) self-reporting; and (6) wealth ranking. Except the household expenditures and income-based methods using uni-dimensional indicators, the remainders approached poverty by multi-dimensional indicators. Among those, wealthranking method is considered comprehensive and most applied in Participatory Poverty Assessment (PPA). Oxfam and ActionAid (2012) have used similar PPA approach for a five-year survey in ten villages throughout Vietnam.

At international level, some multi-dimensional indicators have been developed and applied by international agencies such as HDI, HPI, and MPI. According to Jahan (2002) Human Development Index (HDI) is a measure of average achievement in basic human capabilities. The HDI is an aggregation of three dimensions: long and lengthy life, educational attainment and income. The HDI has a conglomerative perspective while the HPI is considered deprivational (Anand \& Sen, 1997). The HPI is a composite measure of multi-dimensional poverty that measures deprivations in basic human development. It is composed of three dimensions as HDI plus the aspect of participation or social inclusion (Anand \& Sen, 1997, cited in Jahan, 2002). Multidimensional Poverty Index (MPI) is a poverty measure developed by the Oxford Poverty and Human Development Initiative (OPHI) for the United Nation Development Programme (UNDP) and officially used in Human Development Report, which was launched on Nov. 2, 2011. MPI is based on methodology developed by Alkire and Foster (2007), which composes three dimensions (education, health and living standards) and ten indicators with different weights. The Alkire - Foster method is considered flexible and can be used with different dimensions, indicators, weights and cut-offs to create measures specific to different societies and situations.

Following this MPI approach, a study on urban poverty in Vietnam applied an index composed of eight dimensions and 21 indicators with equal weight (Hà Nội People's Committee, HCMC People's Committee \& UNDP, 2010). GSO (2010) and also measured poverty for children through multi-dimensional indicators that include education, health, nutrition, housing, clean water and sanitation, not to work at an early age, entertainment and inclusion, and social protection. Children who do not attain at least two of these eight dimensions are considered multi-dimensional poor. In 2011, UNDP released the Vietnam Human Development Report 2011, which applied three 
methods to measure poverty which are monetary poverty, HPI and MPI. The MPI was based on three dimensions which are health, education and living conditions and nine indicators. People at risk of suffering multiple deprivations - that is those suffering from overlapping deprivations in any two out of nine indicators used are considered poor. However, similar to the above study, there was not any explanation for selected dimensions and indicators.

\section{b. Livelihood Assets and Poverty Elimination:}

Livelihood approach now is commonly practiced in study on socioeconomic characteristics of rural household in developing countries. The livelihood framework identifies five core asset categories or types of capital upon which livelihoods are built. These assets are human capital, natural capital, physical capital, financial capital and social capital. Increasing access -which can take the form of ownership or the right to use - to these assets is considered closely related to support of livelihoods and poverty elimination. Department for International Development of the United Kingdom - DFID (1999) mentioned that the sustainable livelihood approach recognizes the multiple dimensions of poverty identified in participatory poverty assessments. The concept of livelihood assets reflects complexity of socioeconomic and even socio-cultural factors interpreting multi-dimensional poverty. It means multi-dimensional poverty can be interpreted through indicators of livelihood assets and shows that there would be existing solid relations between monetary poverty indicators and the indicators of livelihood assets. Each livelihood asset therefore can be considered as a dimension of poverty which contains several important indicators.

World Bank (2003) mentioned that poverty in Vietnam has a strong spatial dimension. Regional factors affect significantly differences in poverty of each socioeconomic region. The Vietnamese Academy of Social Sciences (2011) showed that characteristics of the poor closely relate to lack of livelihood assets. The qualitative discussion revealed that land (natural asset), lack of credit, in debt, borrowing for food (financial asset), poor housing and furniture (physical asset), young family, limited working experience, lack of knowledge, school leaving, illiteracy, and old/invalid or ill-being household owner (human asset) are main characteristics of the poor. Hà Nội People's Committee, HCMC People's Committee and UNDP (2010) applied MPI approach to choose a set of 21 socioeconomic indicators representative of eight dimensions to measure multi-dimensional poverty in urban Hà Nội and HCMC. 
The study found statistically significant correlations between income and housing service, housing area and quality (physical capital), health, education (human capital), security, social inclusion, and social security (social capital).

The linkage between poverty and other socioeconomic indicators can be found in a variety of empirical studies at international level (Asselin, 2009; Ki, Faye \& Faye, 2009, cited in Asselin, 2009; Crooks, 1995). In Vietnam context, Asselin and Vu developed a five-dimension measurement using dimensions as education, health, water/sanitation, employment and housing (Asselin, 2009).

\section{c. Problems of Data Measurement for Multi-dimensional Poverty:}

Asselin (2009) has deeply exploited various methods to measure multi-dimensional poverty for building a Composite Indicator of Poverty (CIP). Methods as CIP based on Inequality Indices, CIP based on Poverty Structure Analysis, the Fuzzy Subset Approach are discussed. The second method is chosen due to its advantage of using factorial approach. Asselin also emphasizes that Principal Component Analysis requires quantitative indicators while categorical variables are important in survey dataset. Therefore, Multiple Correspondence Analysis (MCA) is suggested to deal with qualitative or categorical indicators, which should be numerically coded. The numeric code can reflect the ordinal structure of the given poverty indicator. Therefore poverty indicators are required to be ordinally corresponding to ordinal scale of poverty. Pure categorical indicator meets the following conditions: (1) it has an ordinal structure; (2) the lowest category refers to an extreme poverty status in reference to the basic need considered, and (3) the highest category is considered as the non-poverty status. This Poverty Structure Analysis using MCA was applied by Ki, Faye and Faye (2009, cited in Asselin, 2009) and Asselin and Vu (2009, cited in Asselin, 2009).

The above literature review allows the conclusion that the nature of poverty is very complicated. Because of its complexity, poverty measurements are very attractive to scientific community worldwide. There are several methods to measure household poverty following uni-dimensional or multi-dimensional approaches. Multidimensional poverty approach is likely to have close linkage with theory of sustainable livelihood. The five livelihood assets of households can be able to reflect household poverty in different aspects through their indicators. The relevant indicators of livelihood assets can be used for multi-dimensional poverty measurement. However, multivariate analysis is required. Principal Components Analysis and Multiple 
Correspondence Analysis are potentially methods to deal with quantitative and categorical variables, respectively.

\section{d. Methodology:}

Sustainable livelihood approach in linking with multi-dimensional poverty is applied in this study. The study assumes that livelihood assets can be used to indicate multi-dimensional poverty though specific indicators.

In order to obtain the above specific objectives, there are several questions that this study has to answer, including:

(1) What are the appropriate socioeconomic indicators representative of multidimensional poverty in linking with livelihood asset?

(2) What are the interrelations in these socioeconomic indicators?

(3) How can the interrelations in these socioeconomic indicators be used to classify households by multi-dimensional poverty?

(4) How does multi-dimensional poverty measurement affect features of rural households in compared to monetary poverty?

The study uses the survey dataset of VHLSS 2008 conducted by GSO. The dataset covers 9,189 households of eight socioeconomic regions. Only 6,837 rural households are selected for analyses. The surveyed indicators are divided into eight categories including (1) Household structure and demographics, (2) Education, (3) Health and health care, (4) Employment and income, (5) Expenditures, (6) Durable goods; (7) Housing, electricity, water, sanitation facilities; and (8) Participation in poverty reduction programs and credit. Nearly thirty socioeconomic indicators are extracted from VHLSS 2008 dataset for the study. They are divided into four categories of livelihood asset. Indicators of social asset are not extracted. The variables include both quantitative and categorical.

Data were analyzed using the following steps:

Step 1: Describe the general socioeconomic features of rural households. Descriptive statistics and correlation analysis will be used in the first step to describe general poverty situation and explore the relations among potential indicators of multidimensional poverty. Correlations between per capita expenditure-based monetary poverty and livelihood asset indicators of households are also identified. 
Step 2: Identify appropriate variables representatives for four livelihood asset components that can be used as aggregated indicators for multi-dimensional poverty. Principal Components Analysis and Multiple Correspondence Analysis will be applied to identify components representative of livelihood asset.

Step 3: Classify rural household by multi-dimensional poverty based on four livelihood asset components identified in Step 2. Clustering Analysis will be used to group observations into different socioeconomic groups on multivariate-analysis technique.

Step 4: Compare household distributions by monetary poverty and multidimensional poverty. Descriptive statistics analysis and Analysis of Variance will be applied to explore advantages and disadvantages of multi-dimensional poverty measurement.

PASW Statistics 18.0 is the software used for statistical analyses in this study.

\section{RESULTS AND DISCUSSION}

\section{a. Results:}

- Preliminary exploration of interrelations among socioeconomic indicators:

In this study, the indicator of monetary-based poverty is measured by expenditure per capita and its quintiles. The indicators of household livelihood assets are both quantitative and categorical. Pearson correlation coefficient is therefore used to measure relations among quantitative indicators while Pearson Chi-square, Likelihood Ratio, Kendall's Tau-b and Spearman Correlation are applied to measure relations among categorical indicators. The preliminary exploration of these relations is summarized in Table 1.

Table 1: Relations Between Expenditure per Capita Quintiles and Categorical Indicators of Household Livelihood Assets

\begin{tabular}{lcccc}
\hline & $\begin{array}{c}\text { Pearson } \\
\text { Chi-Square } \\
\text { Sig. } \\
\text { (2-sided) }\end{array}$ & $\begin{array}{c}\text { Likelihood } \\
\text { Ratio Sig. } \\
\text { (2-sided) }\end{array}$ & $\begin{array}{c}\text { Kendall's } \\
\text { tau-b }\end{array}$ & $\begin{array}{c}\text { Spearman } \\
\text { Correlation }\end{array}$ \\
& $622.087^{* *}$ & $631.938^{* *}$ & $0.071^{* *}$ & $0.082^{* *}$ \\
\hline Highest diploma & $61.94^{* *}$ & $63.95^{* *}$ & $0.031^{* *}$ & $0.034^{* *}$
\end{tabular}


Presence of cart animal

Presence of animal cage

Presence of tractor

Presence of engine boat

Presence of water pump

Presence of vehicle

Presence of motorbike

Presence of mobile phone

Presence of color television

Presence of HF chain

Presence of computer

Presence of refrigerator

Presence of air conditioner

Type of house

Source of consumption water

Presence of tap water

Type of toilet

Electricity source

Presence of credit loan

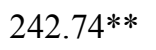

$79.85^{* *}$

$10.45 *$

$27.95 * *$

$89.10 * *$

$61.94 * *$

$242.74^{* *}$

$79.85^{* *}$

$10.45^{*}$

$27.95^{* *}$

$89.10^{* *}$

$89.10^{* *}$

$89.10^{* *}$

$356.95^{* *}$

$619.82 * *$

$77.62 * *$

$1084.05^{* *}$

$310.10^{* *}$

$34.46^{\mathrm{ns}}$
$238.35^{* *}$

$80.05^{* *}$

$10.37 *$

$33.29 * *$

$97.03 * *$

$63.95^{* *}$

$238.35^{* *}$

$80.05^{* *}$

10.37 *

$33.28 * *$

$97.03 * *$

$97.03 * *$

$97.03 * *$

$383.06^{* *}$

$554.36^{* *}$

$80.29 * *$

$1090.51 * *$

$254.76^{* *}$

$34.29^{\text {ns }}$
$-0.065^{* *}$

$0.047 * *$

$0.029 *$

0.030 *

$0.051^{* *}$

$0.031 * *$

$-0.065^{* *}$

$0.047 * *$

$0.029 * *$

0.030 *

$0.051^{* *}$

$0.051 * *$

$0.051^{* *}$

$-0.048 * *$

$0.028 * *$

$0.009^{\text {ns }}$

$0.093 * *$

$0.077 * *$

$-0.009^{\text {ns }}$
$-0.072 * *$

$0.052 * *$

$0.032 * *$

$0.033 * *$

$0.057 * *$

$0.034 * *$

$-0.072 * *$

$0.052 * *$

$0.032 * *$

$0.033 * *$

$0.057 * *$

$0.057 * *$

$0.057 * *$

$-0.056^{* *}$

$0.035 * *$

$0.010^{\text {ns }}$

0.110 **

$0.086^{* *}$

$-0.010^{\mathrm{ns}}$

Source: calculated from VHLSS 2008 dataset

- Application of Principal Component Analysis (PCA) and Multiple Correspondence Analysis (MCA) to detect quantitative indicators of multi-dimensional poverty:

In order to explore potential quantitative indicators of multi-dimensional poverty for rural household in Vietnam, factor analysis is performed. A set of 14 quantitative variables is used including household size, number of sick person, number of sickness day, average day of getting health treatment, average schooling year, total labor, labor working for others, working on-farm, working non-farm, total agricultural cultivated area, housing area, house value, credit loan value and remittance received within a 
year. Extraction method is Principal Component Analysis. Rotation method with Varimax and Kaiser Normalization is applied. The loadings with absolute values less than 0.4 are suppressed from rotation. The results showed that there are six components detected with eigenvalues greater than 1.0 ; and $63.84 \%$ of total variance can be explained by these six components (Table 2).

In order to deal with categorical variables Multiple Correspondence Analysis is employed. Twenty categorical variables selected from the VHLSS 2008 dataset for this statistical procedure. Of which, 15 variables indicating rural household's ownership of common productive and consumption physical properties are in nominal scale. The five remainders are in ordinal scale showing measured order of observed categories. Human asset can be represented by the highest diplomas of household members while physical asset is explained in terms of housing quality (type of house), water source and its quality (consumption water source and consumption water dummy), and type of toilet and electric source.

All variables are numerically coded for calculation. Normalization method by Variable Principal is selected to optimize the association between variables. This method is useful to identify the correlation between the categorical variables.

Four dimensions are selected since they are able to explain for a hundred percent of total variance. Reliability of variable composition in dimensions' structure is confirmed by high values of Cronbach's Alpha coefficients. Results of discrimination measures are presented in Table 3 .

Table 2: Rotated Component Matrix ${ }^{a}$

\begin{tabular}{llllllll}
\hline & \multicolumn{6}{c}{ Component } \\
\cline { 2 - 8 } & 1 & 2 & 3 & 4 & 5 & 6 \\
\hline
\end{tabular}

Total number of household workers

0.943

Household size

0.782

Number of household members working on farm

0.747

Number of household members working for others $\quad 0.558$ $-0.494 \quad-0.441$

Value of house

0.796

Area of housing

0.751

Average schooling years of a household member

0.460 
Average day of treatment of a household member

0.702

Number of sickness day

Number of household's sick person

0.460

Total agricultural cultivated area

Number of household members working non farm 0.908

Remittance value within year

0.922

Note: calculated from VHLSS 2008 dataset

Extraction Method: Principal Component Analysis.

Rotation Method: Varimax with Kaiser Normalization

a. Rotation converged in 9 iterations

Table 3: Discrimination Measures

\begin{tabular}{|c|c|c|c|c|c|}
\hline & & Diı & ion & & \\
\hline & 1 & 2 & 3 & 4 & \\
\hline Highest diploma of household & 0.002 & 0.054 & 0.215 & 0.004 & 0.068 \\
\hline Perennial garden & 0.120 & 0.036 & 0.004 & 0.331 & 0.123 \\
\hline Cart animals & 0.048 & 0.538 & 0.088 & 0.023 & 0.174 \\
\hline Animal cage & 0.010 & 0.478 & 0.162 & 0.060 & 0.177 \\
\hline Tractor & 0.022 & 0.018 & 0.011 & 0.436 & 0.122 \\
\hline Engine boat & 0.084 & 0.033 & 0.031 & 0.092 & 0.060 \\
\hline Water pump & 0.913 & 0.030 & 0.001 & 0.020 & 0.241 \\
\hline Vehicle & 0.120 & 0.036 & 0.004 & 0.331 & 0.123 \\
\hline Motorbike & 0.048 & 0.538 & 0.088 & 0.023 & 0.174 \\
\hline Mobile phone & 0.010 & 0.478 & 0.162 & 0.060 & 0.177 \\
\hline Color television & 0.022 & 0.018 & 0.011 & 0.436 & 0.122 \\
\hline HF chain & 0.084 & 0.033 & 0.031 & 0.092 & 0.060 \\
\hline Computer & 0.913 & 0.030 & 0.001 & 0.020 & 0.241 \\
\hline Refrigerator & 0.913 & 0.030 & 0.001 & 0.020 & 0.241 \\
\hline
\end{tabular}




\begin{tabular}{llllll} 
Air conditioner & 0.913 & 0.030 & 0.001 & 0.020 & 0.241 \\
Type of house & 0.007 & 0.089 & 0.317 & 0.015 & 0.107 \\
Consumption water & 0.047 & 0.272 & 0.414 & 0.068 & 0.200 \\
Consumption water dummy & 0.013 & 0.142 & 0.029 & 0.021 & 0.051 \\
Type of toilet & 0.096 & 0.213 & 0.497 & 0.048 & 0.214 \\
Electricity source & 0.009 & 0.012 & 0.272 & 0.000 & 0.073 \\
\hline Active Total & $\mathbf{4 . 3 9 3}$ & $\mathbf{3 . 1 0 7}$ & $\mathbf{2 . 3 3 7}$ & $\mathbf{2 . 1 1 8}$ & $\mathbf{2 . 9 8 9}$ \\
\hline
\end{tabular}

Note: calculated from VHLSS 2008 dataset

\section{b. Discussion:}

It is likely that there exist close correlations among indicators of human assets. Household size had a positive correlation with household labor indicators. It implies having enough labor force is an advantage of big household. However, increases in household size might lead to increases in sick persons and reduce average treatment day and average schooling year of a household member. A big household was disadvantageous in health care and education in comparison with the small ones.

Related to natural capital, especially agricultural land, big households often had a larger farm scale and abundant labor for on-farm activities. Vice versa, households with smaller farm scale often had more labor working in non-farm sector or working for others. It can be seen that farm scale and distribution of labor in household are closely related. Farm scale also had a positive correlation to the access to bank loans of household.

Concerning the relation between physical assets and financial assets, housing area and value of house had important role for a household in getting access to bank loans. In addition, although housing area also had close relations to household size and number of workers, value of house likely positively related to education level of household members and numbers of non-farm workers. These relations suggest that better education and non-farm activities will contribute better to household income.

Expenditures per capita had a negative correlation to household size, positive correlations to average schooling year and number of non-farm workers. Meanwhile farm scale and numbers of on-farm workers were negatively correlated to expenditure per capita. These results suggest that monetary-based poverty of household had a close 
relation to quality of human asset. Better education and job diversification, as well as less dependency on on-farm activities, are key factors to improve farm income.

Quintiles of expenditure per capita also had very close correlations to almost categorical indicators representative of household's human and physical assets as indicated in Table 1.

For human assets, the better-off and rich quintiles had better level of highest diplomas that their household members attained. Similarly, owning percentages of physical assets increased by richness increase in expenditure per capita. Housing quality and better source of consumption water were also improved for higher quintiles. Only presence of bank loan had no correlation to quintiles of expenditure per capita. In fact, the correlation between these two indicators is probably complicated. Richness implies better physical assets' quantity and value and leads to better opportunity to secure loans because house is considered a kind of mortgage assets. However, bank loan demand of a household might be likely reduced as its richness increases. Therefore, loan demand depends mostly on presence of household business project, its capital size and capital provision capacity of household.

The above analyses on the relations between expenditure per capita of household and other household assets' indicators allow concluding that monetary-based poverty of rural household obviously has close relations to household livelihood assets. In other words, household poverty can be reflected by quantity and quality of livelihood assets. As the results, measures of rural household poverty can be based on a set of indicators representative of livelihood assets at the same time with monetary-based indicators as income or expenditure. Such a multi-dimensional poverty measure can provide an integrated and comprehensive insight of poverty in rural regions of Vietnam.

Results of PCA revealed critical ideas. From Table 2, it is obvious that the first component is composed of four variables which are household size, total household labor, number of household members working on-farm, and number of household members working for others. Except the last variable which has its possible distribution in three components 1,4 and 5 , the first three variables concentrate only in the component 1 . This component refers to human resource of a rural household in terms of quantity and relates closely to agricultural activity. So it can be named as "human resource for agriculture". 
The second component includes two main variables: housing area and house value. It likely indicates physical asset of household through the most important asset, the house. It can be called "housing condition".

The third component includes all three variables indicating health condition of rural household's members. Therefore it can be considered as the "health status" of a rural household. In combination with the component "human resource for agriculture" it reflects household's human asset in terms of labor quantity and health condition of household labor.

Total agricultural cultivated area is representative of the fourth component. This variable indicates clearly the natural asset of a typical rural household in Vietnam that is vital to cropping activity. This component can be named "land resource".

The fifth component includes variable "number of household members working non-farm" with very high loading value. The variable "number of household members working for others" has negative loading values in the component 4 and 5 . These also indicate household labor distribution among types as non-farm, on-farm and working for others. Therefore it should be better located in the fifth component, which likely reveals another side of human asset named "job diversification ability" of rural household.

The sixth component only relates to the variable "remittance received within year". Although only $10 \%$ of surveyed households receive remittance domestically or abroad, it can be an independent supplemented income source for rural households, especially since migration from rural to urban areas has sharply risen during the recent decades. This component can be called "additional income" and considered as representative of the financial asset.

The results of PCA allow selecting six dimensions representing different aspects of rural household livelihood assets.

The human asset can be decomposed into three independent components as "human resource for agriculture", "health status", and "job diversification ability". Human resource for agricultural activities inclines to abundance and availability of labor force of rural households while health status is able to indicate some range of labor quality. Meanwhile the diversification of job is considered a manner to improve rural household income in the context of limited land resource. 
The natural asset is uniquely represented by the component "land resource". Therefore, again statistical result confirms that land is the most important economic asset of rural households.

The physical asset is represented by the component "housing condition" with two typical quantitative variables which are housing area and value of house. The housing condition closely reflects the richness of a household and can be used as the most appropriate indicator of a household physical asset.

The remittance received within year is able to present the component "additional income".

From the MCA results (Table 3), it is likely that Dimension 1 explains owning status of luxury consumption goods for a rural household. Because the variables computer, refrigerator and air conditioner are consumption goods which are rarely used in rural regions, there is no direct correlation between water pump and the other three, Dimension 1 can be representative of luxury consumption goods of a rural household.

Dimension 2 seems to reflect both productive and consumption physical assets. The variables cart animal and animal cage are for the former, and motorbike and mobile phone are for the latter. Similar distribution of categorical variables also occurs to Dimension 4. While the variables tractor and perennial garden represent productive physical assets, vehicle and color television are consumption assets.

Dimension 3 includes variables indicating housing condition, clean water accessibility and hygiene condition. Type of house, electricity source, water source, and type of toilet are really reliable relevant indicators.

From MCA results, it is possible to extract the categorical indicators representative of multi-dimensional poverty. The variables tractor, perennial garden, vehicle and color television can be dropped out because they are not commonly owned by rural households compared with other variables as motorbike, mobile phone, cart animal and animal cage.

The combination of PCA and MCA results allows identifying 23 indicators for livelihood assets of rural household (Table 4). They can be classified in quantitative indicator group (12 variables) and categorical indicator group (11 variables). There are total 10 dimensions of four livelihood assets. Of which, human asset includes three independent dimensions (human resource for agriculture, health status and job diversification ability). Physical asset is composed of five independent dimensions 
(housing condition, housing facilities, productive goods, ordinary consumption goods and luxury consumption goods). Natural asset can be represented by one dimension (land resource). So is financial asset (additional income). Data for social assets are not available from the VHLSS 2008 dataset.

Because the number of extracted variables is still numerous, it can be reduced depending on data availability and on choice of the most appropriate variables. The analysis results give possibility to select different sets of variables depending on availability of data collection. For example, variable "number of household members working on farm" can be dropped out of Dimension 1 because of its low loading value in comparison with the others (Table 2). Similarly, variable "number of household's sick person" can be eliminated from Dimension 2. Concerning physical asset, luxury consumption goods can also be dropped because their presence is rare for rural households. Productive goods as cart animal and animal cage are considered not common and they also depend on agro-ecological conditions, farming habits and specialization of agricultural activities of rural households. These variables should be carefully selected because they are not representative of all cases.

Table 4: Relevant Indicators of Multi-dimensional Poverty under Livelihood Assets Approach

\begin{tabular}{lll}
\hline Livelihood asset & \multicolumn{1}{c}{ Dimension } & \multicolumn{1}{c}{ Relevant indicators } \\
\hline \multirow{3}{*}{ (1) Human asset } & $\begin{array}{l}\text { (1) Human resource for } \\
\text { agriculture }\end{array}$ & $\begin{array}{l}\text { Total number of household workers } \\
\text { Household size } \\
\end{array}$ \\
\cline { 2 - 3 } & & $\begin{array}{l}\text { Number of household members working on } \\
\text { farm* }\end{array}$ \\
& & $\begin{array}{l}\text { Average day of treatment of a household } \\
\text { (2) Health status }\end{array}$ \\
& & $\begin{array}{l}\text { Number of sickness days } \\
\text { Number of household's sick persons* }\end{array}$ \\
\cline { 2 - 3 } & & $\begin{array}{l}\text { Number of household members working } \\
\text { non-farm } \\
\text { (3) Job diversification ability }\end{array}$ \\
& & $\begin{array}{l}\text { Number of household members working for } \\
\text { others }\end{array}$ \\
\hline (2) Natural asset & (4) Land resource & Total agricultural cultivated area \\
\hline
\end{tabular}


(3) Physical asset (5) Housing condition

(6) Housing facilities

(7) Productive goods

(8) Ordinary consumption goods

(9) Luxury consumption goods
House value; Housing area; Type of house

Type of toilet; Water source; Electricity source

Cart animal*; Animal cage*

Motorbike; Mobile phone

Computer*; Refrigerator*; Air conditioner*
(4) Financial asset
(10) Additional income

Remittance received within year

Note: * variables which can be dropped out of calculation for multi-dimensional poverty

Based on these above rationale, there are likely 16 appropriate variables that can be used as livelihood assets' indicators of rural households for further analysis (Table 4). Certainly, variables in the same dimension can be alternatively used. Even so, variables with highest factor loading value or discrimination measure to its component or dimension should be chosen for household livelihood assets.

- Multi-dimensional poverty measurement:

In this section, application possibility of selected variables for measuring multidimensional poverty will be explored by using Cluster Analysis. The method Two Step Cluster Analysis (TSC analysis) is chosen because it provides the following unique features: (1) automatic selection of the best number of clusters, in addition to measures for choosing between cluster models; and (2) ability to create cluster models simultaneously based on categorical and continuous variables. Additionally, this procedure can analyze large data files. TSC analysis assumes variables to be independent; continuous variables are assumed to be normally distributed, while categorical variables are assumed to be multinomial. All continuous variables will be standardized in calculation. Number of clusters is fixed at 5. Schwarz's Bayesian Information Criterion (BIC) is applied. Distance measure method used is Loglikelihood.

To satisfy assumption of independence of variables for clustering, only one variable representative of each dimension of livelihood asset will be used. The selected ones should have the highest correlation values to its dimension. Therefore, six continuous variables including total number of household workers, average day of treatment of a 
household member, numbers of household members working non-farm, total agricultural cultivated area, household value and remittance received within year are selected. In addition, expenditure per capita is also used in calculation to compare to monetary-based poverty classification. Two categorical variables selected are type of toilet and motorbike.

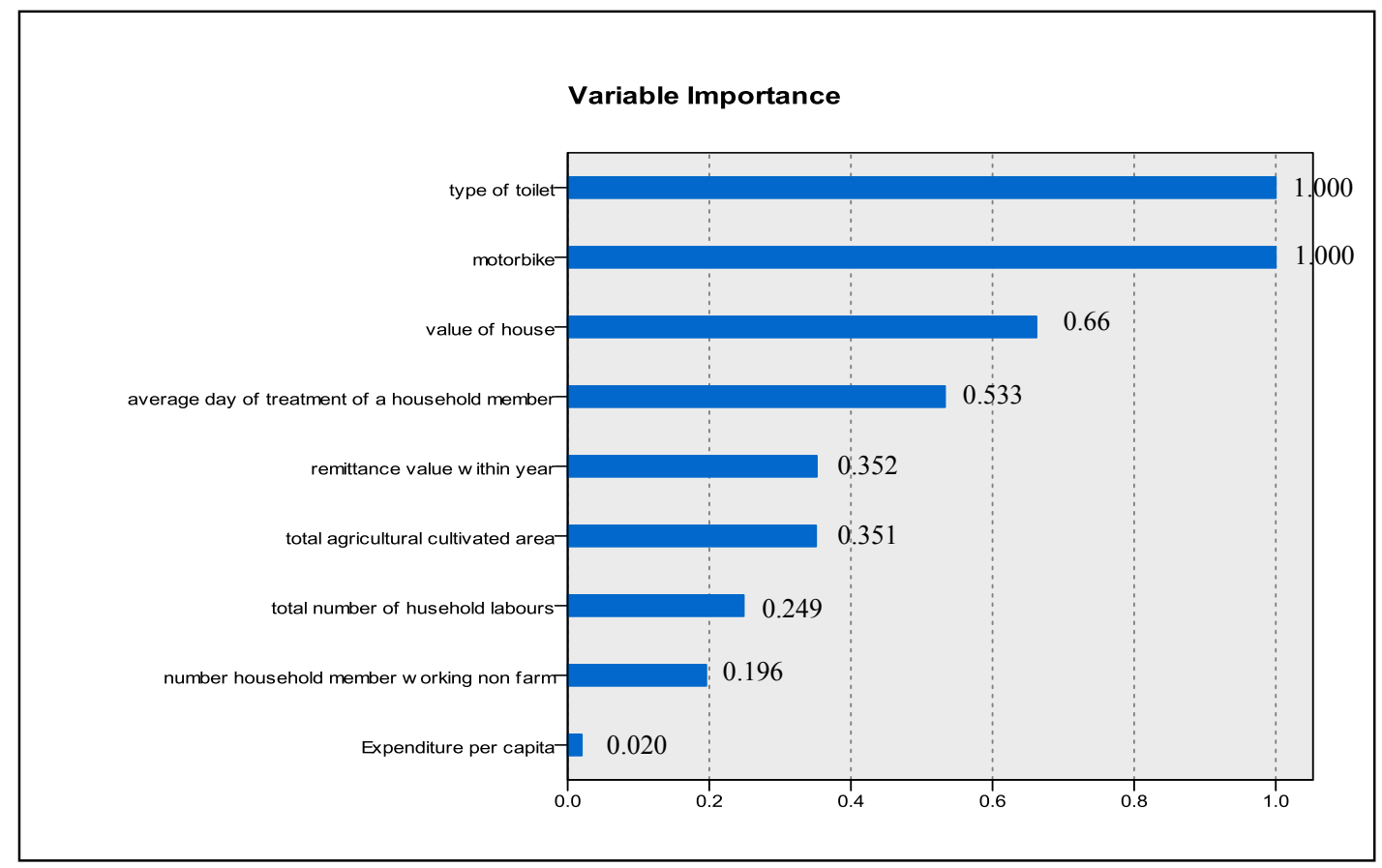

Figure 1: Importance of Multi-dimensional Poverty Indicators for Rural Household Poverty Classification with the Presence of Categorical Variables

TSC analysis results shows that housing facilities (type of toilet) and ordinary consumption goods (motorbike) are likely to have the most important role in multidimensional poverty measurement. The other dimensions as housing condition, human resource for agriculture, job diversification ability and health status play critical roles but their importance level is reduced when housing facilities and ordinary consumption goods are added. Natural asset and financial asset have lower influences on clustering. Surprisingly, expenditure per capita has very weak impact in clustering (Figure 1).

The results suggest some important implications which provide new insight into poverty measurement of rural household in Vietnam context. 
The first implication is that there is a remarkable difference between poverty classification by monetary-based and multi-dimensional approaches. It is likely that expenditure per capita has the lowest influence on multi-dimensional poverty classification. Rural household ability to achieve good housing condition, and better health; abundance of human resource for agricultural activities and job diversification are main factors contributing to household welfare. Therefore, if multi-dimensional approach is applied, poverty structure can be remarkably changed.

The second implication is that livelihood assets dimensions have different contribution levels to multi-dimensional poverty. Dimensions of physical asset and human asset contribute remarkably to multi-dimensional poverty classification while natural asset and financial asset just have the modest roles. In the context of low income, land scarcity and limited financial availability rural households usually rely on human resource to overcome difficulty, especially making use of labor skill to diversify income sources by engaging in self-employment non-farm activities or working for others to earn living.

The third implication is that physical asset dimensions are very critical in showing poorness or richness of rural households in terms of living conditions. More comfortable housing condition, better quality and quantity of owned home comforts as toilet, motorbike, better hygiene water source for consumption, and easy access to electricity are basic indicators of acceptable living standards in rural regions.

The fourth implication is that agricultural land is no longer a precise indicator of poorness or richness for rural households. Land scarcity has become a serious constraint on income improvement and limited ability of income improvement by agricultural activities.

The fifth implication is that remittance is also an important additional income source for rural households. This is an advantage for rural households who have relatives migrating to and working in big cities or abroad.

The last implication is about weights of livelihood dimensions in multi-dimensional poverty measurement. Statistical results show that importance of variables varies over indicators. It suggests that weights of different poverty dimensions are important in measurement of multi-dimensional poverty and values of variable importance might be used as the weights. 
In general, it is clear that the discoveries concerning indicators of multi-dimensional poverty are quite similar to Asselin (2009), Ki, Faye and Faye (2009, cited in Asselin, 2009), Asselin and $\mathrm{Vu}$ (2009) and Crooks (1995) except for the absence of education indicators.

- Comparison of rural household classification by monetary-based and multidimensional poverty:

The distribution of surveyed observations remarkably changes by multidimensional indicators in comparison with that by quintiles of expenditure per capita. All cases are redistributed into five clusters withdrawn from TSC analysis. The involvement of additional eight variables strongly influences distribution of surveyed rural households (Table 5). Rural households in a specific quintile of expenditure per capita can fall into different situations of poorness or richness in getting access to household welfare dimensions. A rural household can fully access one or several socioeconomic dimensions but can inadequately own the other welfare dimensions. As a result, any explanation for the feature and naming of each cluster must be carefully taken.

Table 5: Distribution of Surveyed Observations by Quintiles of Expenditure per Capita and by Clusters

\begin{tabular}{|c|c|c|c|c|c|c|c|c|c|c|c|c|}
\hline \multirow[t]{2}{*}{ Cluster } & \multicolumn{2}{|c|}{ Poor } & \multicolumn{2}{|c|}{ Near poor } & \multicolumn{2}{|c|}{ Middle } & \multicolumn{2}{|c|}{ Better off } & \multicolumn{2}{|c|}{ Rich } & \multicolumn{2}{|c|}{ Total } \\
\hline & obs & $\%$ & obs & $\%$ & obs & $\%$ & obs & $\%$ & obs & $\%$ & obs & $\%$ \\
\hline 1 & 217 & 15.9 & 473 & 36.4 & 370 & 27.1 & 253 & 18.5 & 175 & 12.8 & 1,488 & 21.8 \\
\hline 2 & 154 & 11.3 & 46 & 3.4 & 74 & 5.4 & 101 & 7.4 & 155 & 11.3 & 530 & 7.8 \\
\hline 3 & 318 & 23.3 & 403 & 29.5 & 494 & 36.1 & 428 & 31.3 & 359 & 26.2 & 2,002 & 29.3 \\
\hline 4 & 220 & 16.1 & 361 & 26.4 & 280 & 20.5 & 279 & 20.4 & 225 & 16.4 & 1,365 & 20.0 \\
\hline 5 & 457 & 33.5 & 83 & 6.1 & 148 & 10.8 & 306 & 22.4 & 454 & 33.2 & 1,448 & 21.2 \\
\hline $\mathrm{N}$ & 1,366 & 99.9 & 1,366 & 99.0 & 1,366 & 99.9 & 1,367 & 100 & 1,368 & 99.9 & 6,833 & 99.9 \\
\hline Missing & \multicolumn{2}{|c|}{1} & \multicolumn{2}{|c|}{1} & \multicolumn{2}{|c|}{1} & \multicolumn{2}{|c|}{0} & \multicolumn{2}{|c|}{1} & \multicolumn{2}{|c|}{4} \\
\hline Total & \multicolumn{2}{|c|}{1367} & \multicolumn{2}{|c|}{1367} & \multicolumn{2}{|c|}{1367} & \multicolumn{2}{|c|}{1367} & \multicolumn{2}{|c|}{1369} & \multicolumn{2}{|c|}{6837} \\
\hline
\end{tabular}

Note: calculated from VHLSS 2008 dataset 


\section{CONCLUSION AND POLICY IMPLICATION}

\section{a. Conclusion:}

This article tried to explore interrelations between livelihood assets and poverty in rural Vietnam. Sustainable livelihood approach in linking with multi-dimensional poverty is applied in this study. Such multivariate analysis methods as Principal Component Analysis, Multiple Correspondence Analysis and Cluster Analysis are applied on VHLSS 2008 dataset provided by GSO. The study results allow several conclusions as follows.

Firstly, several socioeconomic indicators can be used to describe multi-dimensional poverty in linking with livelihood assets of rural households in Vietnam. At least ten dimensions are representative of four livelihood assets. Three independent dimensions indicating human assets are human resource for agriculture, health status, and job diversification ability. Physical assets are composed of five independent dimensions which are housing condition, housing facilities, productive goods, ordinary consumption goods and luxury consumption goods. Natural asset is represented by land resource, and financial asset is explained by additional income. In other words, multi-dimensional poverty of rural households in Vietnam can be explained by 10 different socioeconomic aspects.

Secondly, 23 indicators of 10 dimensions extracted from VHLSS 2008 dataset can be used to describe multi-dimensional poverty of rural households. The number of indicators is statistically reduced by choosing the most representative ones for the dimension they indicate. Of which, indicators as the total number of household workers, average day of treatment of a household member, numbers of household members working non-farm, total agricultural cultivated area, household value, remittance received within year, expenditure per capita, type of toilet and motorbike are statistically the most relevant indicators of multi-dimensional poverty.

Thirdly, the resulted indicators have close interrelations to monetary-based poverty. Therefore they can provide better understanding on socioeconomic situation of rural households in multi-dimensional poverty approach.

The study also faces some limitations. Social assets of rural households were not taken into account in analysis. Moreover, only expenditures per capita were used to indicate monetary-based poverty while income per capita would be more relevant. Last but not least, multi-dimensional poverty classification was carried out for all eight 
socioeconomic regions of Vietnam as the whole. As a consequence, differences in regional features would strongly affect the measurement. It implies that multidimensional poverty should be measured separately by socioeconomic region than the whole rural society. These limitations should be addressed in further studies.

\section{b. Policy Implication:}

Multi-dimensional poverty measurement is a critical academic and practical issue to provide insightful and comprehensive understanding of poverty, especially in rural regions where majority of poor households locate in absolute terms. The study approach using PCA, MCA and TSC techniques is feasible and applicable to find relevant socioeconomic indicators of dimensional poverty. The statistically-proved relevant indicators can be used to build a multi-dimensional poverty index such as Composite Indicator of Poverty (CIP) and/or Multi-dimensional Poverty Index (MPI) instead of relying on experience only or simple statistical procedures.

The study results also revealed the importance of using weights for indicators. Three main groups of weights can be withdrawn from Principal Component Analysis, Multiple Correspondence Analysis and Two Step Cluster Analysis. However, it is necessary to identify appropriate techniques to apply the above weights to multidimensional poverty measurement.

Further studies should focus on updated datasets such as the ones in VHLSS 2010. In addition, both income-based and expenditure poverty ought to be applied to compare with multi-dimensional poverty. In particular, the multi-dimensional poverty has to be separately measured by socioeconomic region, and more indicators of social assets must be taken into account

\section{Notes}

[1] Decision No.1143/2000/QĐ-LĐTBXH and Decision No. 170/2005/QĐ-TTg

[2] Result of the Vietnam Household Living Standards Survey 2010.

\section{References}

Alkire, S. \& J. Foster (2008), “Counting and Multi-dimensional Poverty Measurement”, OPHI Working paper No.7, Working paper series, Oxford Poverty and Human Development Initiative.

Anand, S. \& A. Sen (1977), “Concept of Human Development and Poverty: a Multi-dimensional Perspectives", Human Development Papers. 
Asselin, L. M. (2009), Analysis of Multi-dimensional Poverty: Theory and Case Studies, Economic Studies in Inequality, Social Exclusion and Well-Being, Volume No.7. IDRC. Springer.

Chambers, R. \& G.R. Conway (1991), "Sustainable Rural Livelihood: Practical Concepts for the $21^{\text {st }}$ Century", Discussion paper 296, IDS, Brighton: Institute of Development Studies. http://opendocs.ids.ac.uk/opendocs/bitstream/handle/123456789/775/Dp296.pdf?sequence=1 . Consulted on June 10, 2012.

Crooks, D. L. (1995), “American Children at Risk: Poverty and its Consequences for Children's Health, Growth and School Achievement”, Yearbook of Physical Anthropology, 38:57-86.

DFID (1999), "Sustainable Livelihoods Guidance Sheets", http://www.ennonline.net/pool/files/ife/dfid-sustainable-livelihoods-guidance-sheetsection1.pdf. Consulted Oct. 18, 2009.

FAO (2005), Impacts of Policies on Poverty - The Definition of Poverty, EASYPoL, Module 004.

Hà Nội People's Committee, HCMC People's Committee \& UNDP (2010), Đánh giá nghèo đô thị ở Hà Nội và TP. Hồ Chí Minh.

Jahan, S. (2002), "Measuring Human Development: Evolution of the Human Development Index" http://hdr.undp.org/en/media/Jahan_HDI.pdf. UNDP, HDR. Consulted Feb. 16, 2012.

OPHI (2011), "Multi-dimensional Poverty Index 2011", www.ophi.org.uk/wpcontent/uploads/OPHI-MPI-Brief-2011.pdf. Consulted Dec. 12, 2011.

OPHI (2012), "Multi-dimensional Poverty: Alkire Foster Method", http://www.ophi.org.uk/research/multi-dimensional-poverty/, Consulted Dec. 15, 2011.

Oxfam \& ActionAid (2012), Theo dõi nghèo theo phuơng pháp cùng tham gia tại một số cộng đồng dân cu nông thôn Việt Nam, Full report (2007-2011). UKAid, DFID.

UNDP (2011), Social Services for Human Development - Vietnam Human Development Report 2011 (Vietnamese version: Dịch vu xã hội phục vu phát triển con ngưòi - Báo cáo quốc gia về phát triển con người năm 2011).

Viện Khoa học Xã hội Việt Nam (2011), Giảm nghèo ở Việt Nam: Thành tưu và Thách thức.

World Bank (2003), Vietnam Development Report 2004: Poverty, Report No. 27130-VN, Poverty Reduction and Economic Management Unit East Asia and Pacific Region.

World Bank Institute (2005), Introduction to Poverty Analysis, Poverty Manual. 